\title{
A New Method for Solving Transportation Problems Considering Average Penalty
}

\author{
S.M. Abul Kalam Azad ${ }^{1}$, Md. Bellel Hossain ${ }^{2}$ \\ ${ }^{I}$ Department of Mathematics, Rajshahi University of Engineering and Technology, Bangladesh \\ ${ }^{2}$ Department of Mathematics, Rajshahi University of Engineering and Technology, Bangladesh
}

\begin{abstract}
Vogel's Approximation Method (VAM) is one of the conventional methods that gives better Initial Basic Feasible Solution (IBFS) of a Transportation Problem (TP). This method considers the row penalty and column penalty of a Transportation Table (TT) which are the differences between the lowest and next lowest cost of each row and each column of the TT respectively. In a little bit different way, the current method consider the Average Row Penalty (ARP) and Average Column Penalty (ACP) which are the averages of the differences of cell values of each row and each column respectively from the lowest cell value of the corresponding row and column of the TT. Allocations of costs are started in the cell along the row or column which has the highest ARP or ACP. These cells are called basic cells. The details of the developed algorithm with some numerical illustrations are discussed in this article to show that it gives better solution than VAM and some other familiar methods in some cases.
\end{abstract}

Keywords: VAM, IBFS, TP, TT, ARP, ACP

\section{Introduction}

The optimal cost is desirable in the movement of raw materials and goods from the sources to destinations. Mathematical model known as transportation problem tries to provide optimal costs in transportation system. Some well known and long use algorithms to solve transportation problems are Vogel's Approximation Method (VAM), North West Corner (NWC) method, and Matrix Minima method. VAM and matrix minima method always provide IBFS of a transportation problem. Afterwards many researchers provide many methods and algorithms to solve transportation problems. Some of the methods and algorithms that the current research has gone through are: 'Modified Vogel's Approximation Method for Unbalance Transportation Problem' [1] by N. Balakrishnan; Serder Korukoglu and Serkan Balli's 'An Improved Vogel's Approximation Method (IVAM) for the Transportation Problem' [2]; Harvey H. Shore's 'The Transportation Problem and the Vogel's Approximation Method' [3]; 'A modification of Vogel's Approximation Method through the use of Heuristics' [4] by D.G. Shimshak, J.A. Kaslik and T.D. Barelay; A. R. Khan's 'A Re-solution of the Transportation Problem: An Algorithmic Approach' [5]; 'A new approach for finding an Optimal Solution for Trasportation Problems' by V.J. Sudhakar, N. Arunnsankar, and T. Karpagam [6]. Kasana and Kumar [7] bring in extreme difference method calculating the penalty by taking the differences of the highest cost and lowest cost in each row and each column. The above mentioned algorithms are beneficial to find the IBFS to solve transportation problems. Besides, the current research also presents a useful algorithm which gives a better IBFS in this topic.

\section{Algorithm}

Step 1 Subtract the smallest entry from each of the elements of every row of the TT and place them on the right-top of corresponding elements.

Step 2 Apply the same operation on each of the columns and place them on the right-bottom of the corresponding elements.

Step 3 Place the Average Row Penalty (ARP) and the Average Column Penalty (ACP) just after and below the supply and demand amount respectively within first brackets, which are the averages of the right-top elements of each row and the right-bottom elements of each column respectively of the TT.

Step 4 Identify the highest element among the ARPs and ACPs, if there are two or more highest elements; choose the highest element along which the smallest cost element is present. If there are two or more smallest elements, choose any one of them arbitrarily.

Step 5 Allocate $x_{i j}=\min \left(a_{i}, b_{j}\right)$ on the left top of the smallest entry in the $(i, j)$ th of the TT.

Step 6 If $a_{i}<b_{j}$, leave the ith row and readjust $b_{j}$ as $b_{j}^{\prime}=b_{j}-a_{i}$.

If $a_{i}>b_{j}$, leave the jth column and readjust $a_{i}$ as $a_{i}^{\prime}=a_{i}-b_{j}$. 
If $a_{i}=b_{j}$, leave either ith row or $\mathrm{j}$-th column but not both.

Step 7 Repeat Steps 1 to 6 until the rim requirement satisfied.

Step 8 Calculate $z=\sum_{i=1}^{m} \sum_{j=1}^{n} c_{i j} x_{i j}$, z being the minimum transportation cost and $c_{i j}$ are the cost elements of the TT.

\section{Illustration 01}

\section{Numerical Illustrations}

The per unit transportation cost (in thousand dollar) and the supply and demand (in number) of motor bikes of different factories and showrooms are given in the following transportation table.

\begin{tabular}{|c|c|c|c|c|c|}
\hline \multirow{2}{*}{ Factories } & \multicolumn{4}{|c|}{ Showrooms } & \multirow{2}{*}{ Supply $\left(a_{i}\right.$} \\
\hline & $\mathrm{D}_{1}$ & $\mathrm{D}_{2}$ & $\mathrm{D}_{3}$ & $\mathrm{D}_{4}$ & \\
\hline $\mathrm{W}_{1}$ & 9 & 8 & 5 & 7 & 12 \\
\hline $\mathrm{W}_{2}$ & 4 & 6 & 8 & 7 & 14 \\
\hline $\mathrm{W}_{3}$ & 5 & 8 & 9 & 5 & 16 \\
\hline Demand $\left(b_{j}\right)$ & 8 & 18 & 13 & 3 & 42 \\
\hline
\end{tabular}

Table: 1.1

We want to solve the transportation problem by the current algorithm.

\section{Solution}

The row differences and column differences are:

\begin{tabular}{|c|c|c|c|c|c|}
\hline \multirow{2}{*}{ Factories } & \multicolumn{4}{|c|}{ Showrooms } & \multirow{2}{*}{ Supply } \\
\cline { 2 - 5 } & $\mathrm{D}_{1}$ & $\mathrm{D}_{2}$ & $\mathrm{D}_{3}$ & $\mathrm{D}_{4}$ & \\
\hline $\mathrm{W}_{1}$ & $9_{5}^{4}$ & $8_{2}^{3}$ & $5_{0}^{0}$ & $7_{2}^{2}$ & 12 \\
\hline $\mathrm{W}_{2}$ & $4_{0}^{0}$ & $6_{0}^{2}$ & $8_{3}^{4}$ & $7_{2}^{3}$ & 14 \\
\hline $\mathrm{W}_{3}$ & $5_{1}^{0}$ & $8_{2}^{3}$ & $9_{4}^{4}$ & $5_{0}^{0}$ & 16 \\
\hline Demand & 8 & 18 & 13 & 3 & 42 \\
\hline
\end{tabular}

Table: 1.2

The allocations with the help of ARP and ACP are:

\begin{tabular}{|c|c|c|c|c|c|c|c|c|c|}
\hline \multirow[t]{2}{*}{ Factories } & \multicolumn{4}{|c|}{ Showrooms } & \multirow[t]{2}{*}{ Supply } & & & & \\
\hline & $D_{1}$ & $\mathrm{D}_{2}$ & $\mathrm{D}_{3}$ & $\mathrm{D}_{4}$ & & \multicolumn{4}{|c|}{ ARP } \\
\hline $\mathrm{W}_{1}$ & 9 & 8 & ${ }^{12} 5$ & 7 & 12 & $(2.2)$ & - & - & - \\
\hline $\mathrm{W}_{2}$ & 84 & ${ }^{6} 6$ & 8 & 7 & 14 & $(2.2)$ & $(2.2)$ & (1) & (1) \\
\hline $\mathrm{W}_{3}$ & 5 & ${ }^{12} 8$ & ${ }^{1} 9$ & ${ }^{3} 5$ & 16 & (1.7) & (1.7) & (2.3) & $(0.5)$ \\
\hline Demand & 8 & 18 & 13 & 3 & 42 & & & & \\
\hline \multirow{4}{*}{ ঠે } & (2) & (1.3) & (2.3) & (1.3) & & & & & \\
\hline & $(0.5)$ & (1) & $(0.5)$ & (1) & & & & & \\
\hline & - & (1) & $(0.5)$ & (1) & & & & & \\
\hline & - & (1) & $(0.5)$ & - & & & & & \\
\hline
\end{tabular}

Table: 1.3

The transportation cost is $z=\sum_{i=1}^{m} \sum_{j=1}^{n} c_{i j} x_{i j}$

$$
\begin{aligned}
z & =5 \times 12+4 \times 8+6 \times 6+8 \times 12+9 \times 1+5 \times 3 \\
& =248 \$
\end{aligned}
$$

\section{Illustration 02}

A company manufactures Toy Robots for children and it has three factories $S_{1}, S_{2}$ and $S_{3}$ whose weekly production capacities are 3,7 and 5 hundred pieces respectively. The company supplies Toy Robots to its four showrooms located at $D_{1}, D_{2}, D_{3}$ and $D_{4}$ whose weekly demands are 4, 3, 4 and 4 hundred pieces respectively. The transportation costs per hundred pieces of Toy Robots are given below in the Transportation Table: 


\begin{tabular}{|c|c|c|c|c|c|}
\hline \multirow[t]{2}{*}{ Factories } & \multicolumn{4}{|c|}{ Showrooms } & \multirow{2}{*}{$\begin{array}{c}\text { Supply } \\
a_{i}\end{array}$} \\
\hline & $\mathrm{D}_{1}$ & $\mathrm{D}_{2}$ & $\mathrm{D}_{3}$ & $\mathrm{D}_{4}$ & \\
\hline $\mathrm{S}_{1}$ & 2 & 2 & 2 & 1 & 3 \\
\hline $\mathrm{S}_{2}$ & 10 & 8 & 5 & 4 & 7 \\
\hline $\mathrm{S}_{3}$ & 7 & 6 & 6 & 8 & 5 \\
\hline Demand $b_{j}$ & 4 & 3 & 4 & 4 & 15 \\
\hline
\end{tabular}

Table: 2.1

We want to solve the transportation problem by the current algorithm.

\section{Solution:}

The row differences and column differences are:

\begin{tabular}{|l|l|c|c|c|c|c|}
\hline \multicolumn{2}{|c|}{ Factories } & \multicolumn{4}{c|}{ Showrooms } & \multirow{2}{*}{$\begin{array}{c}\text { Supply } \\
a_{i}\end{array}$} \\
\cline { 3 - 6 } \multicolumn{2}{|c|}{} & $\mathrm{D}_{1}$ & $\mathrm{D}_{2}$ & $\mathrm{D}_{3}$ & $\mathrm{D}_{4}$ & \\
\hline \multirow{2}{*}{$\mathrm{S}_{1}$} & $2_{0}^{1}$ & $2_{0}^{1}$ & $2_{0}^{1}$ & $1_{0}^{0}$ & 3 \\
\hline $\mathrm{S}_{2}$ & $10_{8}^{6}$ & $8_{6}^{4}$ & $5_{3}^{1}$ & $4_{3}^{0}$ & 7 \\
\hline & $\mathrm{S}_{3}$ & $7_{5}^{1}$ & $6_{4}^{0}$ & $6_{4}^{0}$ & $8_{7}^{2}$ & 5 \\
\hline \multicolumn{2}{|l|}{ Demand $b_{j}$} & 4 & 3 & 4 & 4 & 15 \\
\hline
\end{tabular}

Table: 2.2

The allocations with the help of ARP and ACP are:

\begin{tabular}{|c|c|c|c|c|c|c|c|c|c|}
\hline \multirow[t]{2}{*}{ Factories } & \multicolumn{4}{|c|}{ Showrooms } & \multirow{2}{*}{$\begin{array}{l}\text { Supply } \\
\qquad a_{i}\end{array}$} & \multirow{2}{*}{\multicolumn{4}{|c|}{ ARP }} \\
\hline & $\mathrm{D}_{1}$ & $\mathrm{D}_{2}$ & $\mathrm{D}_{3}$ & $\mathrm{D}_{4}$ & & & & & \\
\hline $\mathrm{S}_{1}$ & ${ }^{3} 2$ & 2 & 2 & 1 & 3 & $(0.7)$ & - & - & - \\
\hline $\mathrm{S}_{2}$ & 10 & 8 & 35 & ${ }^{4} 4$ & 7 & $(2.7)$ & $(2.7)$ & $(2.6)$ & - \\
\hline $\mathrm{S}_{3}$ & ${ }^{1} 7$ & ${ }^{3} 6$ & ${ }^{1} 6$ & 8 & 5 & $(0.7)$ & $(0.7)$ & $(0.3)$ & $(0.3)$ \\
\hline Demand $b_{j}$ & 4 & 3 & 4 & 4 & 15 & & & & \\
\hline \multirow{4}{*}{$\stackrel{\circlearrowright}{\mho}$} & $(4.3)$ & (3.3) & $(2.3)$ & (3.3) & & & & & \\
\hline & $(1.5)$ & $(1)$ & $(0.5)$ & $(2)$ & & & & & \\
\hline & $(1.5)$ & $(1)$ & $(0.5)$ & - & & & & & \\
\hline & - & - & & - & & & & & \\
\hline
\end{tabular}

Table: 2.3

The transportation cost is $z=\sum_{i=1}^{m} \sum_{j=1}^{n} c_{i j} x_{i j}$

$$
\begin{aligned}
z & =2 \times 3+5 \times 3+4 \times 4+7 \times 3+7 \times 1+6 \times 3+6 \times 1 \\
& =68 \text { units. }
\end{aligned}
$$

\section{Illustration 03}

A company manufactures toilet tissues and it has three factories $S_{1}, S_{2}$ and $S_{3}$ whose weekly production capacities are 9,8 and 10 thousand pieces of toilet tissues respectively. The company supplies tissues to its three showrooms located at $\mathrm{D}_{1}, \mathrm{D}_{2}$ and $\mathrm{D}_{3}$ whose weekly demands are 7,12 and 8 thousand pieces respectively. The transportation costs per thousand pieces are given in the next Transportation Table:

\begin{tabular}{|c|c|c|c|c|}
\hline \multirow{2}{*}{ Factories } & \multicolumn{3}{|c|}{ Showrooms } & \multirow{2}{*}{ Supply $a_{i}$} \\
\cline { 2 - 4 } & $\mathrm{D}_{1}$ & $\mathrm{D}_{2}$ & $\mathrm{D}_{3}$ & \\
\hline $\mathrm{S}_{1}$ & 4 & 3 & 5 & 9 \\
\hline $\mathrm{S}_{2}$ & 6 & 5 & 4 & 10 \\
\hline $\mathrm{S}_{3}$ & 8 & 10 & 7 & 27 \\
\hline \multirow{2}{*}{ Demand $b_{j}$} & 7 & 12 & 8 & \\
\hline
\end{tabular}

Table: 3.1 


\section{Solution:}

The row differences and column differences are:

\begin{tabular}{|c|c|c|c|c|}
\hline \multirow{2}{*}{ Factories } & \multicolumn{3}{|c|}{ Showrooms } & \multirow{2}{*}{ Supply } \\
\cline { 2 - 4 } $\mathrm{S}_{1}$ & $\mathrm{D}_{1}$ & $\mathrm{D}_{2}$ & $\mathrm{D}_{3}$ & \multirow{0}{*}{$4_{0}^{1}$} \\
$\mathrm{3}_{0}^{0}$ & $5_{1}^{2}$ & 9 \\
\hline $\mathrm{S}_{2}$ & $6_{2}^{2}$ & $5_{2}^{1}$ & $4_{0}^{0}$ & 8 \\
\hline $\mathrm{S}_{3}$ & $8_{4}^{1}$ & $10_{7}^{3}$ & $7_{3}^{0}$ & 10 \\
\hline Demand & 7 & 12 & 8 & 27 \\
\hline
\end{tabular}

Table: 3.2

The allocations with the help of ARP and ACP are:

\begin{tabular}{|c|c|c|c|c|c|c|c|}
\hline \multirow{2}{*}{ Factories } & \multicolumn{3}{|c|}{ Showrooms } & \multirow[t]{2}{*}{ Supply } & \multirow{2}{*}{\multicolumn{3}{|c|}{ ARP }} \\
\hline & $\mathrm{D}_{1}$ & $\mathrm{D}_{2}$ & $\mathrm{D}_{3}$ & & & & \\
\hline $\mathrm{S}_{1}$ & 4 & 3 & 5 & 9 & $(1)$ & - & - \\
\hline $\mathrm{S}_{2}$ & 6 & ${ }^{3} 5$ & ${ }^{5} 4$ & 8 & (1) & (1) & (1) \\
\hline $\mathrm{S}_{3}$ & 8 & 10 & ${ }^{3} 7$ & 10 & (1.3) & $(1.3)$ & $(0.5)$ \\
\hline Demand & 7 & 12 & 8 & 27 & & & \\
\hline \multirow{3}{*}{ 己 } & (2) & (3) & $(1.3)$ & & & & \\
\hline & $(1)$ & $(2.5)$ & (1.5) & & & & \\
\hline & $(1)$ & - & $(1.5)$ & & & & \\
\hline
\end{tabular}

Table: 3.3

The transportation cost is $z=\sum_{i=1}^{m} \sum_{j=1}^{n} c_{i j} x_{i j}$

$$
\begin{aligned}
z & =3 \times 9+5 \times 3+4 \times 5+8 \times 7+7 \times 3 \\
& =139 \text { units. }
\end{aligned}
$$

\section{Comparison of Results}

The developed algorithm in the current work gives optimal or near optimal solution. However, a comparison of the current work with the three existing conventional methods is presented in case of the three above illustrations.

\begin{tabular}{|l|c|c|c|}
\hline \multirow{2}{*}{ Methods } & \multicolumn{3}{|c|}{ Solutions } \\
\cline { 2 - 4 } & Illustration -1 & Illustration -2 & Illustration -3 \\
\hline Current Method & 248 & 68 & 139 \\
\hline North-West Corner Method & 320 & 93 & 150 \\
\hline Matrix Minima Method & 248 & 79 & 145 \\
\hline VAM & 248 & 68 & 150 \\
\hline Optimal Solution & 240 & 68 & 139 \\
\hline
\end{tabular}

Table: 4

\section{Conclusion}

The current method considers all the opportunity costs or penalty in a transportation table by taking averages of the penalties. On the other hand, some other methods take some of the penalties only (ie. the lowest and the next lowest, the highest and the lowest etc.). The outcomes of the present algorithm are optimal or near optimal solutions while several examples were tested.

\section{References}

[1] N. Balakrishnan, 'Modified Vogel's Approximation Method for Unbalance Transportation Problem,' Applied Mathematics Letters 3(2), 9,11,1990.

[2] Serdar Korukoglu and Serkan Balli, ‘An Improved Vogel's Approximation Method for the Transportation Problem', Association for Scientific Research, Mathematical and Computational Application Vol.16 No.2, 370-381, 2011.

[3] H.H. Shore, 'The Transportation Problem and the Vogel's Approximation Method', Decision Science 1(3-4), 441-457, 1970.

[4] D.G. Shimshak, J.A. Kaslik and T.D. Barelay, 'A modification of Vogel's Approximation Method through the use of Heuristics', Infor 19,259-263, 1981.

[5] Aminur Rahman Khan, 'A Re-solution of the Transportation Problem: An Algorithmic Approach' Jahangirnagar University Journal of Science, Vol. 34, No. 2, 49-62, 2011.

[6] V.J. Sudhakar, N. Arunnsankar, T. Karpagam, 'A new approach for find an Optimal Solution for Trasportation Problems', European Journal of Scientific Research 68 254-257, 2012.

[7] H.S. Kasana and K.D. Kumar, 'Introductory Operation Research: Theory and Applications', Springer PP, 509-511, 2004. 